\title{
Opleiding als sociale scheidslijn
}

\author{
Marloes De Lange, Jochem Tolsma \& Maarten H.J. Wolbers ${ }^{*}$
}

\section{Onderwijs als $\mathbf{x}$-factor}

In de afgelopen tien jaar is er een stortvloed aan talentenshows ontstaan op de Nederlandse televisie. $\mathrm{Na}$ het verdwijnen van Henny Huismans jarenlang succesvolle Soundsmixshow in 2002, waarin onbekende Nederlanders live hun zangtalent ten gehore konden brengen, werd de ene na de andere talentenjacht gelanceerd. Idols, X-Factor, Popstars en The Voice of Holland zijn stuk voor stuk bij de massa geliefde televisieshows, net als programma's als Holland's Got Talent, De Beste Singer-Songwriter van Nederland en So You Think You Can Dance. Het idee achter dergelijke shows is om de doorsnee, nog onbekende Nederlander de kans te geven zijn (of haar) talent niet langer verborgen te houden en hem, onder begeleiding van professionals, op weg te helpen naar een glansrijke carrière in bijvoorbeeld de muziek- of dansindustrie. Dat het daarbij puur om talent gaat en het blootleggen van kwaliteiten, wordt het sterkst benadrukt in het format van The Voice of Holland. In dit programma vinden zogeheten blinde audities plaats, wat betekent dat juryleden de deelnemers enkel kunnen horen en niet kunnen zien, waardoor zij slechts op hun zangkwaliteit worden beoordeeld en uiterlijk en bekendheid geen rol kunnen spelen in de beslissing van de jury.

Talentenjachten als The Voice of Holland vertonen veel overeenkomsten met het huidige Nederlandse onderwijs zoals dat de afgelopen decennia vorm is gegeven. De nadruk is hierbij, met name vanaf de jaren zestig van de vorige eeuw, komen te liggen op het creëren van gelijke kansen voor iedereen. De aandacht groeide voor het ontwikkelen van talent onder kinderen uit (met name) lagere sociale milieus, die daar tot dan toe geen mogelijkheden voor hadden binnen het onderwijs (Inspectie van het Onderwijs, 2012). Waar afkomst tot die tijd bepaalde of je, simpel gezegd, boer of advocaat zou worden, is geleidelijk aan de gedachte gaan overheersen dat dit niet langer acceptabel was, maar ook niet economisch efficient is. In plaats daarvan streeft de Nederlandse overheid er sinds de Tweede Wereldoorlog naar dat ieder individu op basis van zijn eigen talent en inzet een eerlijke positie in de maatschappij kan bereiken (RMO, 2011). Ook een boerenzoon zou het dus moeten kunnen schoppen tot advocaat. Dit vormt een typisch voorbeeld van laten opbloeien van 'verborgen talent', waar Van Heek in zijn studie eind jaren zestig van de vorige eeuw aandacht voor vroeg (Van Heek e.a., 1968). Dit gelijkheidsprincipe, namelijk dat je als individu beloond wordt op basis van je eigen merites, ofwel eigen verdiensten of kwaliteiten, en niet die van je

* Dr. Marloes de Lange is als docent verbonden aan de leerstoelgroep Sociologie van Consumptie en Huishoudens van Wageningen UR. Dr. Jochem Tolsma is als universitair hoofddocent verbonden aan de sectie Sociologie van de Radboud Universiteit. Prof. dr. Maarten H.J. Wolbers is als hoogleraar onderzoek van onderwijs verbonden aan de sectie Sociologie van de Radboud Universiteit. 
ouders, werd de basis van het huidige Nederlandse onderwijssysteem. De Nederlandse overheid heeft hier dan ook fors in geïnvesteerd en actief beleid gevoerd om sociale stijging onder alle lagen van de bevolking te stimuleren (RMO, 2011), zoals het breed toegankelijk maken van het hoger onderwijs. Het gevolg van deze meritocratisering van het onderwijs is dat Nederland zich sinds de jaren zestig heeft ontvouwd tot een open samenleving: sociale herkomst is minder bepalend voor het onderwijssucces van kinderen en daarmee indirect ook voor succes op de arbeidsmarkt, terwijl opleiding belangrijker is geworden voor het verwerven van een goede beroepspositie (De Graaf \& Luijkx, 1995), ook al wordt deze laatste bevinding recent in twijfel getrokken (Tolsma \& Wolbers, 2010b, 2014).

Ondanks haar positieve uitwerking heeft de meritocratisering van het onderwijs geleid tot maatschappelijke discussie op verschillende punten. Dit heeft enerzijds te maken met de mate waarin onderwijstalenten (en de daarmee samenhangende kansen) in onze samenleving eerlijk verdeeld zijn en anderzijds met de nadelige gevolgen van selecteren op talenten en vroege wapenfeiten binnen het onderwijssysteem. Hoewel de openheid in de Nederlandse samenleving tot vrij recent toenam door sociale stijging van kinderen uit lagere sociale milieus, heeft het selecteren op talent ook tot gevolg dat sociale daling, ofwel het bereiken van een lagere maatschappelijke positie dan je ouders, een fenomeen is dat sinds kort steeds vaker (onder mannen) voorkomt (Tolsma \& Wolbers, 2010a). De vraag is welke gevolgen sociale daling heeft voor een individu. Bereiken sociale dalers een lager welvaartsniveau dan hun ouders, bijvoorbeeld, of voelen zij wellicht een zekere mate van onrust en onzekerheid als gevolg van sociale daling (RMO, 2011)? Ook rijst de vraag of het streven naar nog verdere openheid in de samenleving niet op gespannen voet staat met de wens voor een gemiddeld hoger opgeleide bevolking in Nederland. Immers, een keerzijde van (nog) meer openheid is dat toekomstige generaties mogelijk lager op de maatschappelijke ladder uitkomen dan hun ouders.

De toegenomen openheid kent echter nog een belangrijke keerzijde. Door de afgenomen invloed van sociale herkomst op iemands maatschappelijke positie en door het toegenomen belang van de eigen behaalde opleiding is het de vraag in hoeverre opleiding een, of zelfs dé nieuwe sociale scheidslijn is in Nederland. Dat wil zeggen: is het zo dat verschillende opleidingsgroepen eigen instituties, houdingen, herkenbare leefstijlen, et cetera krijgen? En brokkelt hierdoor wellicht de samenhang in de samenleving af tussen individuen met verschillende opleidingsniveaus, evenals hun tolerantie ten opzichte van elkaar? Kortom, de angst heerst dat opleiding de bron vormt van het ontstaan van nieuwe vormen van sociale ongelijkheid in de Nederlandse samenleving.

\section{Vals spelen}

Hoewel ieder individu tegenwoordig - in ieder geval in theorie - de kans krijgt via het onderwijs sociaal hogerop te komen ten opzichte van zijn ouders, zal het opleidingsniveau van een kind altijd in meer of mindere mate samenhangen met het sociaal milieu waar het vandaan komt. Dit heeft te maken met de 'erfelijkheid' 
van talenten, die doorgaans in grotere mate aanwezig zijn binnen hogere sociale milieus. Intelligentie is deels genetisch bepaald, wat een positieve invloed heeft op de hoogte van het te bereiken opleidingsniveau. Daarnaast vindt er echter ook sociale en culturele overdracht van talenten plaats, waarbij het gaat om persoonsgebonden factoren zoals creativiteit, doorzettingsvermogen, omgangsvormen en taalvaardigheid, die hooggewaardeerd worden en maatschappelijk succes bevorderen (De Beer, 2013). Deze overdracht van talenten vindt plaats via opvoeding en socialisatie, en draagt positief bij aan het te bereiken opleidingsniveau van individuen. Gerelateerd hieraan speelt ook de positieve samenhang tussen de aanwezigheid van ouderlijke hulpbronnen, die van belang zijn voor de ontwikkeling van talent, met name tijdens de eerste levensjaren van een kind, en sociale herkomst een rol. Het gaat hierbij om economische, sociale en culturele hulpbronnen (Van Eijck \& Kraaykamp, 2009). Voorbeelden hiervan zijn de keuze van ouders voor een kwalitatief goede school en de hulp die zij geven bij huiswerk en extra begeleiding (zoals examentrainingen). Hoger opgeleide ouders zijn doorgaans beter in staat zulke keuzes te maken of dergelijke hulp te bieden, wat het opleidingsniveau van hun kinderen positief beïnvloedt. Tot slot spelen aspiraties een rol bij verschillen in onderwijskeuzes van kinderen uit hogere en lagere sociale milieus. Omdat ouders graag willen dat hun kinderen niet in een lager sociaal milieu terechtkomen dan zijzelf, doen ouders uit hogere sociale milieus er alles aan hun kinderen een succesvolle onderwijsloopbaan te laten doorlopen (Breen \& Goldthorpe, 1997). Zelfs als kinderen uit hogere en lagere sociale milieus over dezelfde cognitieve vaardigheden beschikken, behalen kinderen uit hogere sociale milieus een hoger opleidingsniveau dan kinderen uit lagere, omdat de ouders van de eerstgenoemde groep kinderen het nut van onderwijs vaker inzien (Boudon, 1974; Kloosterman \& De Graaf, 2009).

Kinderen uit de hogere sociale milieus hebben dus vrijwel altijd een voorsprong in het onderwijs ten opzichte van kinderen uit de lagere sociale milieus. Hierdoor blijft sociale herkomst altijd (enige) invloed uitoefenen op de hoogte van iemands opleidingsniveau en de maatschappelijke positie die hij daar uiteindelijk mee bereikt. Tegelijk met de vraag of opleiding dé nieuwe sociale scheidslijn in de Nederlandse samenleving aan het worden is, rijst daarom de vraag in hoeverre de oude scheidslijn naar sociale herkomst van belang blijft. Opnieuw kunnen we in dit opzicht de link leggen met de talentenshows op de Nederlandse televisie waarin het volgens de programmamakers enkel om talent zou draaien. Critici van deze talentenjachten benadrukken echter de onzichtbaarheid en onduidelijkheid met betrekking tot de selectiecriteria van deelnemers tijdens de voorrondes, die nog niet op televisie worden getoond. Zo lijkt het geen toeval te zijn dat de halfzus van de bekende songwriter John Ewbank, Jennifer Ewbank, in 2010 als deelneemster verscheen in The Voice of Holland. Ook Charlotte ten Brink, de dochter van televisiepresentator Robert ten Brink, dook in 2009 op als deelneemster aan Popstars en werd een jaar later gevraagd mee te doen aan de eerste editie van The Voice of Holland, aldus haar eigen website. In hoeverre er in deze talentenjachten nu een eerlijke strijd plaatsvindt op basis van talent of dat afkomst toch een rol speelt, valt dus te betwisten, net als dat de strijd die in het onderwijs gestreden 
wordt om het bereiken van een zo hoog mogelijk opleidingsniveau door kinderen uit uiteenlopende sociale milieus niet puur en alleen op talent gebaseerd zal zijn.

\section{Ons onderzoek}

In het boek Opleiding als sociale scheidslijn. Een nieuw perspectief op een oude kloof (De Lange, Tolsma \& Wolbers, 2015) hebben we een antwoord trachten te formuleren op de vraag of er sprake is van een toenemende scheidslijn tussen hoger en lager opgeleiden in Nederland. Men spreekt over een sociale scheidslijn als minimaal twee van de volgende elementen samenkomen: (1) er is sprake van duidelijk te onderscheiden groepen van aanzienlijke omvang, (2) deze groepen hebben verschillende opvattingen, gedragingen en levenskansen, en (3) er vindt identificatie plaats met de groep en er zijn groepsspecifieke instituties. De groep hoger opgeleiden is de afgelopen decennia flink gegroeid in Nederland, en hoger en lager opgeleiden zijn getalsmatig nu ongeveer in evenwicht met elkaar. Dus aan de eerste voorwaarde is voldaan. Aan de andere kant is er nog nauwelijks sprake van het ontstaan van instituties voor en door specifieke opleidingsgroepen. Dus, om na te gaan of er sprake is van een (nieuwe) sociale scheidslijn, hebben we vooral gekeken of er verschillen zijn tussen lager en hoger opgeleiden in houdingen en gedrag en, vervolgens, of deze zijn toegenomen in de loop van de tijd. Indien er eerst geen verschillen tussen opleidingsgroepen waren en nu wel, dan kan men spreken van een nieuwe scheidslijn. Maar ook indien de opleidingsverschillen gelijk zijn gebleven en tegelijkertijd oude scheidslijnen, zoals naar sociale herkomst, aan belang hebben ingeboet, is er sprake van een opleidingsscheidslijn die relatief aan belang heeft gewonnen.

Lange tijd is binnen de sociale stratificatiesociologie de overheersende gedachte geweest dat ondanks de voortschrijdende modernisering de invloed van sociale herkomst in westerse landen min of meer constant blijft, en de titels van invloedrijke boeken zoals The constant flux (Erikson \& Goldthorpe, 1992) en Persistent inequality (Shavit \& Blossfeld, 1993) gaven hier uiting aan. Nederland werd overigens wel gezien als een van de mogelijke uitzonderingen op deze sociale wet, omdat Nederlandse sociologen in de jaren negentig van de vorige eeuw al een afname zagen in de invloed van sociale herkomst op onderwijskansen (De Graaf \& Ganzeboom, 1993; Wolbers \& De Graaf, 1996) en beroepssucces (De Graaf \& Luijkx, 1995). Meer recentelijk is echter duidelijk geworden dat de invloed van het sociaal milieu op opleiding en beroepspositie ook in andere landen in de afgelopen decennia is afgenomen (Breen, 2004). Niet alleen de bevindingen van sociologen, maar ook de titels van hun artikelen veranderden mee, blijkend uit titels als 'Persistent inequalities?' (Ballarino e.a., 2009) en 'Non-persistent inequality in educational attainment' (Breen e.a., 2009). Zeer recentelijk wordt echter weer rekening gehouden met een toename in het relatieve belang van sociale herkomst in vergelijking met het eigen behaalde opleidingsniveau, doordat de opwaardering van de arbeidsmarkt de onderwijsexpansie niet heeft kunnen bijbenen en er sprake is van diploma-inflatie (Tolsma \& Wolbers, 2014). Het is dan ook nog een open vraag of sociale herkomst aan belang heeft ingeboet ten opzichte van oplei- 
ding. Daarom hebben we in ons boek vooral de sterkte van de opleidingsscheidslijn vergeleken met de sterkte van de scheidslijn naar sociale herkomst.

De vraag of opleiding een nieuwe scheidslijn is, krijgt veel belangstelling de afgelopen jaren. Meest recent nog in twee rapporten van het Sociaal en Cultureel Planbureau (SCP) die eind 2014 verschenen: Gescheiden werelden (een gezamenlijke publicatie met de Wetenschappelijke Raad voor het Regeringsbeleid) (SCP/ WRR, 2014) en Verschil in Nederland (SCP, 2014). Hoewel hierin de suggestie wordt gewekt dat een antwoord wordt gegeven op bovengenoemde vraag, vindt feitelijk alleen een beschrijving plaats van de huidige sociale segmentatie op het structurele en sociaal-culturele vlak. Daarmee wordt weliswaar aangetoond dat opleiding tegenwoordig op diverse maatschappelijke domeinen een belangrijke scheidslijn is in de Nederlandse samenleving, maar niet of de rol van opleiding in de loop van de tijd meer bepalend is geworden en hoe deze zich verhoudt tot de scheidslijn naar sociale herkomst.

In ons boek hebben we het tijdsperspectief expliciet gemaakt door voor uiteenlopende maatschappelijke domeinen te onderzoeken in hoeverre in de afgelopen decennia de kloof tussen lager en hoger opgeleiden is toegenomen en in hoeverre deze scheidslijn belangrijker is geworden dan de oude scheidslijn naar sociale herkomst. Het gaat daarbij om de domeinen arbeidsmarkt, attitudes, politieke participatie en gezondheid. We zijn afgegaan op patronen en trends die gevonden zijn in een uitvoerige empirische analyse van bestaande, grootschalige dataverzamelingen. Het betreft gegevens afkomstig van twee langlopende, herhaaldelijk gehouden enquêtes onder steekproeven van leden van de Nederlandse samenleving die een representatieve afspiegeling vormen van de totale bevolking op dat moment, te weten de Familie-enquête Nederlandse Bevolking (FNB) en Sociaalculturele Ontwikkelingen in Nederland (SOCON).

De resultaten laten zien dat opleiding een duidelijke scheidslijn vormt in de Nederlandse samenleving in de onderzochte periode (1979-2011). Op alle vier de maatschappelijke domeinen nemen we beduidende verschillen waar tussen hoger en lager opgeleiden. Op de arbeidsmarkt nemen hoger opgeleiden een gunstigere positie in dan lager opgeleiden: ze hebben vaker een betaalde baan en een baan met een hogere beroepsstatus. Daarnaast hebben hoger opgeleide vrouwen vaker dan lager opgeleide vrouwen een baan voor minimaal 32 uur in de week. Wat betreft verschillen in attitudes geldt dat lager opgeleiden over het algemeen meer traditionele of conservatieve houdingen hebben dan hoger opgeleiden: ze hebben een meer traditionele houding ten aanzien van man-vrouwverschillen, zijn minder vaak voorstander van abortus en vaker voorstander van overheidsmaatregelen, en staan negatiever ten aanzien van etnische minderheden en de Europese Unie. Hoewel de verschillen in politieke participatie niet groot zijn, geldt dat hoger opgeleiden politiek actiever zijn dan lager opgeleiden: ze hebben vaker de intentie om te gaan stemmen bij Tweede Kamerverkiezingen en zijn vaker lid van een politieke partij. Tot slot blijkt de gezondheid van hoger opgeleiden in het algemeen beter te zijn dan van lager opgeleiden: hoger opgeleiden voelen zich gezonder dan lager opgeleiden en hebben minder vaak last van (ernstig) overgewicht. 
Hoewel er dus een duidelijke kloof bestaat tussen hoger en lager opgeleiden in Nederland, geldt in het algemeen niet dat opleiding de nieuwe sociale scheidslijn is geworden. De opleidingskloof is voor veel indicatoren stabiel. Dat betekent dat de verschillen tussen hoger en lager opgeleiden vaak altijd al aanwezig zijn geweest (binnen de geobserveerde periode) en niet zijn veranderd. Indien hoger en lager opgeleiden wel zijn veranderd in opvattingen of gedrag over de tijd, zijn de veranderingen vaak even sterk en in dezelfde richting, waardoor de opleidingskloof niet in grootte is gewijzigd. Op het domein van politieke participatie en gezondheid geldt voor alle indicatoren dat bestaande opleidingsverschillen over de tijd stabiel zijn gebleven en opleiding dus geen nieuwe sociale scheidslijn vormt. Op het domein van de arbeidsmarkt en attitudes geldt dit voor mannen, maar niet zonder meer voor vrouwen. De verschillen in arbeidsmarktdeelname tussen hoger en lager opgeleide vrouwen zijn steeds groter geworden, maar de verschillen in het aantal uren dat zij werken zijn juist gereduceerd. Hoewel lager opgeleide vrouwen dus nog altijd minder vaak werken dan hoger opgeleide vrouwen, verschilt de grootte van hun aanstelling tegenwoordig niet meer. Op het domein van attitudes doen zich tegengestelde ontwikkelingen in de opleidingskloof onder vrouwen voor. Wat betreft oude, traditionele thema's als man-vrouwverschillen en abortus vormt opleiding tegenwoordig geen duidelijke scheidslijn meer. Wat betreft nieuwe thema's, als overheidsmaatregelen, etnische minderheden en de Europese Unie, is opleiding wel als sociale scheidslijn toegenomen in (een deel van) de periode 1979-2011.

Ook relatief ten opzichte van de oude scheidslijn naar sociale herkomst is de constatering dat de scheidslijn naar opleiding niet in belang is toegenomen in de periode 1979-2011. Opnieuw geldt op het domein van politieke participatie en gezondheid dat opleiding geen toenemende sociale scheidslijn vormt relatief ten opzichte van sociale herkomst. Voor mannen geldt dit wederom ook op het domein van de arbeidsmarkt en attitudes. Op het domein van de arbeidsmarkt zien we voor vrouwen wel dat de eigen opleiding steeds belangrijker is geworden ten opzichte van sociale herkomst, maar enkel wat betreft hun deelname op de arbeidsmarkt en vervolgens niet voor wat betreft het aantal uren dat zij werken of de beroepsstatus van hun baan. Op het domein van attitudes stellen we vast dat opleiding enkel voor de houding van vrouwen ten aanzien van overheidsmaatregelen belangrijker is geworden dan sociale herkomst in de loop van de tijd, terwijl opleiding juist relatief minder belangrijk is geworden vergeleken met sociale herkomst wat betreft oude thema's als man-vrouwverschillen (ook onder mannen) en abortus.

\section{Conclusie}

$\mathrm{Al}$ met al is het gerechtvaardigd om te stellen dat in Nederland opleiding een belangrijke scheidslijn is op tal van maatschappelijke domeinen. Er is een aanzienlijke kloof tussen hoger en lager opgeleiden op het vlak van de arbeidsmarkt, attitudes, politieke participatie en gezondheid. Ondanks deze alom aanwezige kloof tussen hoger en lager opgeleiden, is het niet zo dat opleiding steeds meer 
bepalend is geworden voor wat betreft individuele kansen in de samenleving. Er is immers geen consistente verandering in het opleidingseffect op de verschillende maatschappelijke domeinen geconstateerd: soms dicht de kloof, soms wordt die allengs dieper. Ook is het relatieve belang van opleiding niet sterker geworden ten opzichte van sociale herkomst. Opleiding is dus niet als de nieuwe sociale scheidslijn te bestempelen. Opleiding was dat al en is het nog steeds.

Het bieden van breed toegankelijk onderwijs heeft ertoe geleid dat sociale herkomst in de voorbije decennia minder belangrijk is geworden voor het verwerven van een goede maatschappelijke positie, en sociale stijging steeds vaker mogelijk werd, maar de keerzijde hiervan is ook dat opleiding ongelijkheden creëert op tal van maatschappelijke domeinen. Het onderwijs kent dus twee gezichten: het is een gelijkmaker én sociale scheidslijn (Wolbers, 2014). Maar de rol van sociale herkomst is zeker nog niet uitgespeeld. Op de arbeidsmarkt bestaat er ook nu nog een directe invloed van sociale herkomst op de bereikte beroeps- en inkomenspositie van individuen. Bovendien is er geen sprake van volledige meritocratie in het onderwijs: getalenteerde individuen komen zeker verder in het onderwijs dan voorheen, maar ook degenen die beschikken over veel economische, culturele en sociale hulpbronnen van de ouders hebben daar nog steeds profijt van tijdens de onderwijsloopbaan (Tieben, 2010). Het plan om gratis schoolboeken in het voortgezet onderwijs weer af te schaffen, het verdwijnen van kleine (dorps)scholen, de toenemende populariteit van particuliere bijlessen en de invoering van het sociaal leenstelsel in het hoger onderwijs zullen mogelijk de invloed van deze hulpbronnen in het Nederlandse onderwijs zelfs weer doen toenemen. Om op de metafoor uit de inleiding terug te komen: het onderwijs is een $\mathrm{x}$-factor waar het hoofdzakelijk draait om eigen talenten, maar er wordt wel degelijk vals gespeeld door de hulp(bronnen) van anderen in te schakelen.

\section{Literatuur}

Ballarino, G., Bernardi, F., Requena, M., \& Schadee, H. (2009). Persistent inequalities? Expansion of education and class inequality in Italy and Spain. European Sociological Review, 25: 123-138.

Beer, P. de (2013). Nieuwe ongelijkheid in een 'winner take all'-samenleving. Socialisme \& Democratie, 70: 34-45.

Boudon, R. (1974). Education, opportunity, and social inequality. New York: Wiley.

Breen, R. (red.) (2004). Social mobility in Europe. Oxford: Oxford University Press.

Breen, R., \& Goldthorpe, J.H. (1997). Explaining educational differentials: Towards a formal rational action theory. Rationality and Society, 9: 275-305.

Breen, L., Luijkx, R., Müller, W., \& Pollak, R. (2009). Non-persistent inequality in educational attainment: Evidence from eight European countries. American Journal of Sociology, 114: 1475-1521.

Eijck, K. van, \& Kraaykamp, G. (2009). De intergenerationele reproductie van cultureel kapitaal in belichaamde, geïnstitutionaliseerde en geobjectiveerde vorm. Mens \& Maatschappij, 84: 177-206.

Erikson, R., \& Goldthorpe, J.H. (1992). The constant flux: A study of class mobility in industrial societies. Oxford: Oxford University Press. 
Graaf, P.M. de, \& Ganzeboom, H.B.G. (1993). Family background and educational attainment in the Netherlands for the 1891-1960 birth cohorts. In: Y. Shavit \& H.P. Blossfeld (red.), Persistent inequality. Changing educational attainment in thirteen countries. Boulder/San Francisco/Oxford: Westview Press, 75-100.

Graaf, P.M. de, \& Luijkx, R. (1995). Paden naar succes: geboorte of diploma's? In: J. Dronkers \& W.C. Ultee (red.), Verschuivende ongelijkheid in Nederland: Sociale gelaagdheid en mobiliteit. Assen: Van Gorcum, 31-45.

Heek, F. van, e.a. (1968). Het verborgen talent. Meppel: Boom.

Inspectie van het Onderwijs (2012). Van latent naar talent. Een inventariserend onderzoek naar talentontwikkeling in het voortgezet onderwijs. Utrecht: Inspectie van het Onderwijs.

Kloosterman, R., \& Graaf, P.M. de (2009). Zittenblijven of afstromen? De relatie tussen sociaal milieu en keuzes in het voortgezet onderwijs voor drie cohorten leerlingen. Mens \& Maatschappij, 84: 5-28.

Lange, M. de, Tolsma, J., \& Wolbers, M.H.J. (2015). Opleiding als sociale scheidslijn. Een nieuw perspectief op een oude kloof. Antwerpen/Apeldoorn: Garant.

RMO (2011). Nieuwe ronde, nieuwe kansen. Sociale stijging en daling in perspectief. Den Haag: Raad voor Maatschappelijke Ontwikkeling.

SCP (2014). Verschil in Nederland. Den Haag: Sociaal en Cultureel Planbureau.

SCP/WRR (2014). Gescheiden werelden. Den Haag: Sociaal en Cultureel Planbureau/Wetenschappelijke Raad voor Regeringsbeleid.

Shavit, Y., \& Blossfeld, H.P. (red.) (1993). Persistent inequality. Changing educational attainment in thirteen countries. Boulder, CO: Westview Press.

Tieben, N. (2010). Transitions, tracks and transformations. Social inequality in transitions into, through and out of secondary education in the Netherlands for cohorts born between 1914 and 1985 (dissertatie). Nijmegen: Radboud Universiteit.

Tolsma, J., \& Wolbers, M.H.J. (2010a). Naar een open samenleving? Recente ontwikkelingen in sociale stijging en daling in Nederland. Den Haag: Raad voor Maatschappelijke Ontwikkeling.

Tolsma, J., \& Wolbers, M.H.J. (2010b). Onderwijs als nieuwe sociale scheidslijn? De gevolgen van onderwijsexpansie voor sociale mobiliteit, de waarde van diploma's en het relatieve belang van opleiding in Nederland. Tijdschrift voor Sociologie, 31: 239-259.

Tolsma, J., \& Wolbers, M.H.J. (2014). Social origin and occupational success at labour market entry in the Netherlands, 1931-80. Acta Sociologica, 57: 253-269.

Wolbers, M.H.J. (2014). De twee gezichten van het onderwijs (inaugurele rede Radboud Universiteit, Nijmegen).

Wolbers, M.H.J., \& Graaf, P.M. de (1996). Onderwijsexpansie of meritocratisering? Een verklaring voor de afgenomen samenhang tussen het ouderlijk sociaal milieu en het hoogst bereikte opleidingsniveau van kinderen. Tijdschrift voor Onderwijsresearch, 21: 117-132. 